\title{
ONOMÁVAEIN
}

Revista semestral de lingüística, filología y traducción

\section{Perfil del teletraductor en Argentina, Chile y España: las TIC aplicadas a la práctica profesional}

Teletranslator's profile in Argentine, Chile and Spain:

TICs applied to professional practice

\section{María Isabel Diéguez Morales \\ Pontificia Universidad Católica de Chile \\ Chile}

\section{Rosa María Lazo Rodríguez \\ Pontificia Universidad Católica de Chile Chile}

\section{Camilo Quezada Gaponov}

Pontificia Universidad Católica de Chile Chile

M. Isabel Diéguez: Programa de Traducción, Facultad de Letras, Pontificia Universidad Católica de Chile. Correo electrónico: mdieguez@uc.cl

Rosa María Lazo: Programa de Traducción, Facultad de Letras, Pontificia Universidad Católica de Chile. Correo electrónico: rlazo@uc.cl

Camilo Quezada: Escuela de Psicología, Pontificia Universidad Católica de Chile.

Correo electrónico: cequezad@uc.cl 


\section{Resumen}

Con el fin de describir las principales características del trabajo que realizan teletraductores residentes en Argentina, Chile y España, entre mayo y julio de 2011 se llevó a cabo un estudio de mercado de la traducción, en el cual se aplicó una encuesta en línea que respondieron 1.073 profesionales. La información obtenida fue contrastada entre los profesionales de los tres países y, en el caso de algunos ítems referidos a los residentes en Chile, se compararon los datos con los obtenidos en dos estudios de mercado anteriores (2006/2008) realizados a nivel nacional. Los resultados de esta investigación han permitido actualizar y optimizar el Magíster en Traducción y el Diploma de especialización en TIC aplicadas a la traducción que ofrece el Programa de Traducción de la Pontificia Universidad Católica de Chile. En este artículo se exponen datos referidos al ámbito de la teletraducción, es decir, a la aplicación de las TIC en la práctica profesional de los traductores.

Palabras clave: estudio de mercado; teletraducción; perfil del teletraductor; TIC aplicadas a la práctica profesional.

\section{Abstract}

In order to describe the main characteristics of the work that teletranslators resident in Argentine, Chile and Spain perform, 1,073 professional translators participated in the 2011 survey. The data collected was contrasted by countries, and some data of former studies (2006 and 2008) concerning residents in Chile was compared with the results of the present study. The results of this quantitative and descriptive research were used to update and optimize the Master in Translation and the Diploma in Translation and TICS offered by the Translation Program at our University. We hope that the data can also be useful for other universities that train professional teletranslators. In this article we present data related to teletranslation, that is, TICs applied to the professional practice of translators.

Keywords: market study; teletranslation; teletranslator's profile; TICs applied to the professional practice. 


\section{Introducción}

El Programa de Traducción de la Facultad de Letras de la Pontificia Universidad Católica de Chile creó el año 2007 el Diploma de especialización "Traducción y tecnologías de la información y la comunicación", dirigido a traductores profesionales. Dos años más tarde, se creó el Magíster en Traducción, programa de posgrado de orientación profesional dirigido a licenciados universitarios. Ambos programas contemplan una especialización en teletraducción, definida como la aplicación al ámbito de la traducción profesional de tecnologías de la información y la comunicación. Con el fin de implementary optimizar dichos programas académicos, el equipo de investigadores del BTUC, banco terminológico de la PUC de Chile, ha realizado dos estudios de mercado de la traducción (2006 y 2008) a nivel nacional, los cuales han arrojado resultados sobre diferentes características del trabajo profesional del traductor, como, por ejemplo, pares de lengua, áreas temáticas, tipos y formatos de textos, herramientas informáticas generales y específicas aplicadas a la traducción, entre otros.

En el año 2011, con motivo de la celebración de los 40 años de la carrera de traducción UC, se llevó a cabo un nuevo estudio de mercado (Diéguez y otros, 2012), en el cual la muestra se amplió a otros países con el fin de poder comparar el trabajo que realizan los traductores residentes en Chile con la práctica llevada a cabo por profesionales residentes en Argentina y España. Además, este nuevo estudio descriptivo ha permitido comparar, en el caso de los traductores residentes en Chile, la evolución de algunas características de su trabajo, tomando como base los resultados obtenidos en el estudio 2011 y en las encuestas aplicadas los años 2006 y 2008.

En una publicación anterior (Diéguez y otros, 2014) se expusieron datos del estudio de mercado 2011 relacionados con años de trabajo como traductor, tipo de estudios superiores, interés por estudios de perfeccionamiento y actualización, lenguas de trabajo, áreas temáticas y tipos de textos. En este artículo nos hemos propuesto describir los resultados relacionados con la aplicación de las TIC, generales y específicas, al trabajo profesional de los teletraductores y para ello nos hemos planteado los siguientes objetivos:

a) Describir y comparar las características del trabajo que realizan teletraductores residentes en Argentina, Chile y España, relacionadas con la aplicación de las TIC generales y específicas en la práctica profesional de la traducción.

b) En el caso de los teletraductores residentes en Chile, realizar un análisis comparativo de algunos ítems tomando como referencia los estudios de mercado realizados los años 2006 y 2008.

Algunas de las preguntas de investigación que orientan este estudio de mercado son las siguientes: ¿Cuál es la forma de trabajo de estos profesionales?, ¿con qué tipo de clientes trabajan?, ¿de qué forma delegan trabajo en sus colegas?, ¿qué modalidades de traducción practican?, ¿con qué tipo de formatos de documentos trabajan?, ¿qué recursos informáticos y memorias de traducción utilizan en su trabajo y cuál es su nivel o grado de dominio de dichos recursos?

\section{Metodología de trabajo}

Para cumplir los objetivos propuestos y responder las preguntas de investigación, los datos se recolectaron mediante una encuesta en línea dirigida a traductores profesionales que residen en Argentina, Chile y España, quienes respondieron el cuestionario entre junio y agosto de $2011^{1}$. Los datos obtenidos se procesaron y analizaron tanto en términos generales como por 
país. Posteriormente, algunos resultados de los traductores residentes en Chile del estudio 2011 fueron comparados con los resultados de las encuestas 2006 y 2008; estos corresponden a ítems incluidos en las encuestas anteriores como, por ejemplo, forma de trabajo, tipo de clientes, tipo de formato y uso de programas informáticos y memorias de traducción.

En la encuesta participaron 1.073 traductores profesionales residentes en Argentina (394), Chile (309) y España (370) y consta de 24 preguntas; los ítems 1, 2 y 3 eran obligatorios y los ítems 4 al 22, opcionales.

Como uno de los objetivos de esta encuesta fue comparar las características del trabajo que realizan traductores profesionales residentes en Argentina, Chile y España, el análisis de la mayoría de los ítems incluirá, cuando corresponda, un informe para el total de respuestas y un desglose comparativo por país.

\section{Resultados}

A continuación se presentan los resultados que dicen relación con "forma de trabajo", "tipo de clientes", "forma de delegar trabajo", "modalidades de traducción", "tipos de formatos", "uso y nivel de dominio de recursos informáticos" y "uso y nivel de dominio de memorias de traducción”.

\subsection{Forma de trabajo}

La modalidad de trabajo más frecuente (344) fue "Jornada completa en forma independiente". La segunda alternativa más frecuente (124) fue la que combina el trabajo en alguna organización y empresa con el trabajo independiente. Esto significa que más de la mitad de los traductores que respondieron la pregunta trabaja en forma independiente, ya sea en forma totalmente independiente o combinando esta modalidad con el trabajo en alguna organización. En tercer y cuarto lugar se ubican las alternativas "Trabajo media jornada como traductor" (112) y "Otra al- ternativa” (101). En cuanto a esta última, se destacan, entre otras, el trabajo como gerente de una agencia de traducción, como director(a) de una carrera universitaria de traducción y el trabajo de traductor(a) compartido con otra profesión como profesor(a) de lenguas o ingeniero(a). Cifras muy bajas presentan las alternativas "Trabajo jornada completa en una agencia de traducción" (27) y "Trabajo jornada completa en una organización o empresa" (34), como se puede observar en el gráfico 1.

\section{GRÁFICO 1}

Forma de trabajo como traductor

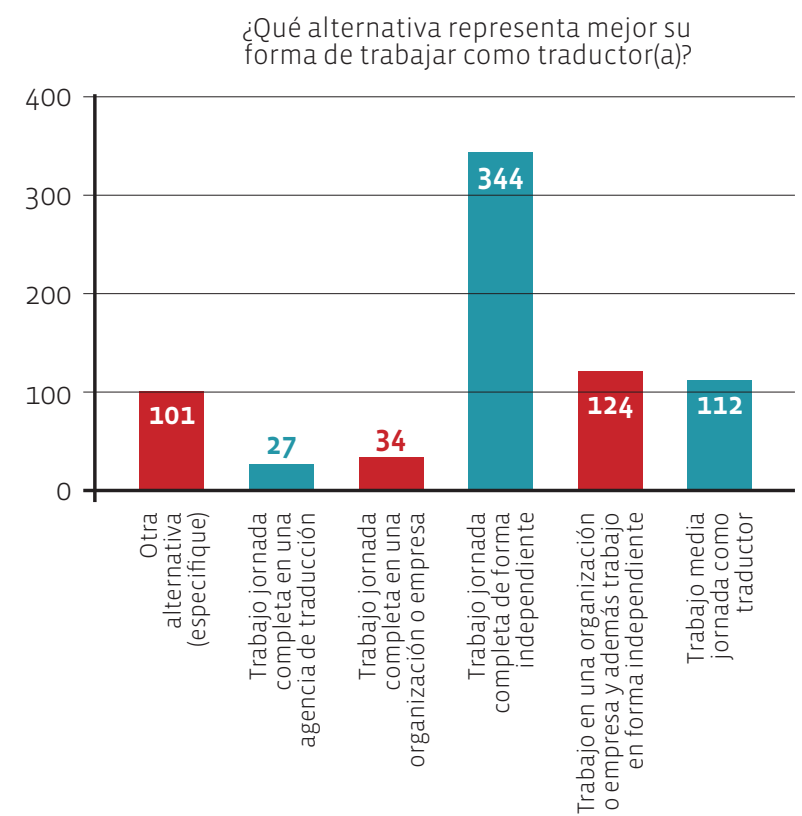

Al revisar los resultados por país (cf. gráfico 2), se constata que el total de 742 respuestas se distribuye de manera relativamente equitativa en los tres países (Argentina 285, Chile 203 y España 254). La alternativa "Trabajo jornada completa en forma independiente" es la más seleccionada en los tres países, superando ampliamente a las demás (Argentina 138, Chile 77 y España 129). En cuanto a la cantidad de traductores que trabaja a tiempo completo en alguna agencia de traducción, si bien la cantidad total de respuestas es muy baja (27), el desglose por país es bastante desbalanceado: 14 para Argentina, 3 para Chile y 10 para España. Por su parte, la alternativa "Tra- 


\section{GRÁFICO 2}

Forma de trabajo como traductor por país

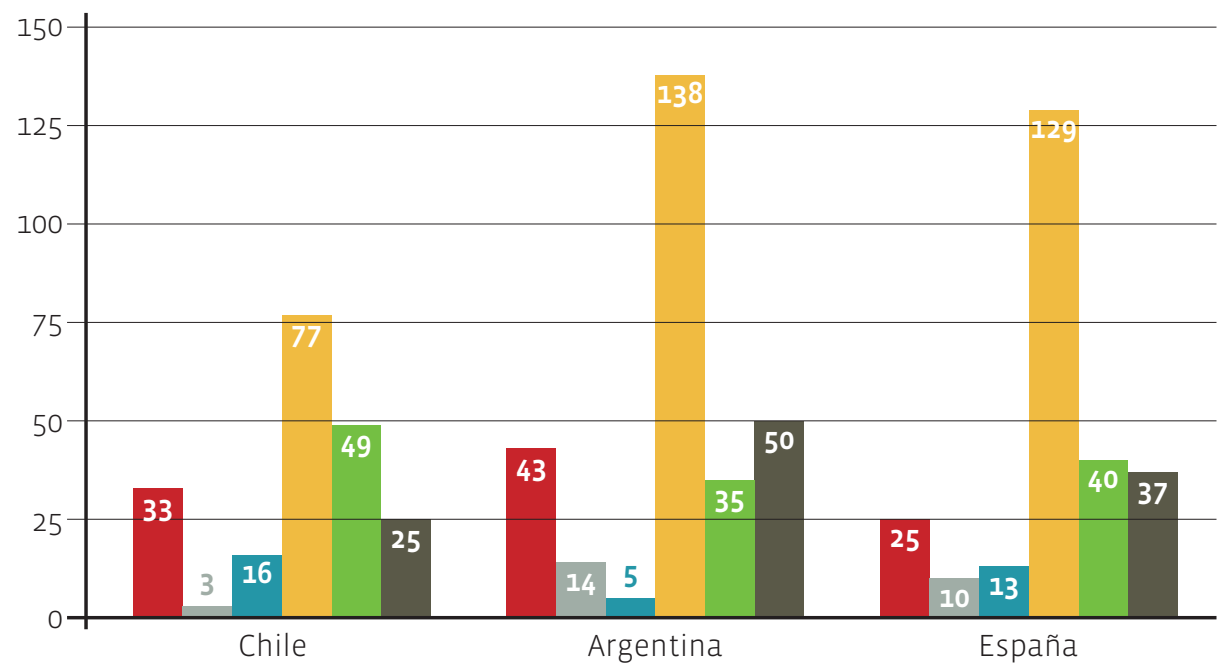

¿Qué alternativa representa mejor su forma de trabajar como traductor(a)?

Otra alternativa (especifique)

Trabajo jornada completa en una agencia de traducción

Trabajo jornada completa en una organización o empresa

Trabajo jornada completa en forma independiente

Trabajo en una organización o empresa y además trabajo en forma independiente

Trabajo media jornada como traductor bajo jornada completa en una organización o empresa" también presenta diferencias por país. En este caso, llama la atención que, de las 34 respuestas, 16 corresponden a traductores residentes en Chile, seguido de 13 traductores residentes en España y solo 5 traductores de Argentina.

\subsection{Tipos de clientes de los traductores que trabajan en forma independiente}

Al revisar las respuestas del total de la muestra (cf. gráfico 3), se puede ver que el tipo de cliente más reportado corresponde a "Clientes directos nacionales" (523). En segundo y tercer lugar aparecen las "Agencias de traducción", ya sean internacionales (336) o nacionales (287). A su vez, 275 traductores señalaron trabajar con clientes directos internacionales.

Al observar los datos por país, se constata que la distribución de las respuestas para la opción más frecuente, "Clientes directos nacionales", es bastante pareja en los tres países (Argentina 198, Chile 161 y España 164). No obstante, se observan diferencias al comparar otros tipos de clientes, como, por ejemplo, las "Agencias de traducción nacionales” (cf. gráfico 4), ya que solo 44 traductores residentes en Chile reporta-

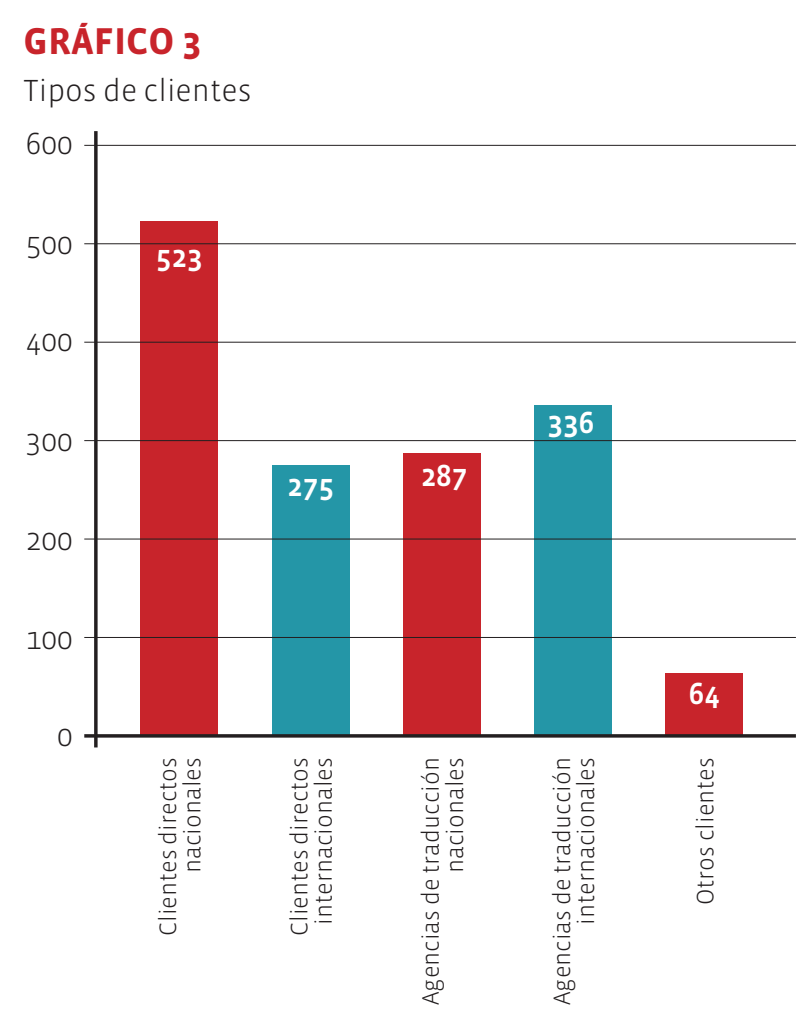

ron trabajar frecuentemente para ellas, lo que contrasta con los 107 traductores de Argentina y los 136 traductores de España. Si se observa la cantidad de traductores residentes en Chile que afirmó trabajar para "Agencias de traducción 
internacionales" (cf. gráfico 5), la diferencia es aún mayor: 62 en el caso Chile, frente a 135 y 139 registrados en Argentina y España, respectivamente. Cabe acotar que una cantidad menor de traductores (64) marcó la alternativa "otros clientes", cifra que se distribuyó en forma muy pareja en los tres países (Argentina 23, Chile 20 y España 21). Dentro de "otros clientes", los traductores señalaron trabajar en estudios de doblaje y de subtitulación, editoriales y agencias de publicidad.

\section{GRÁFICO 4}

Agencias de traducción nacionales por país

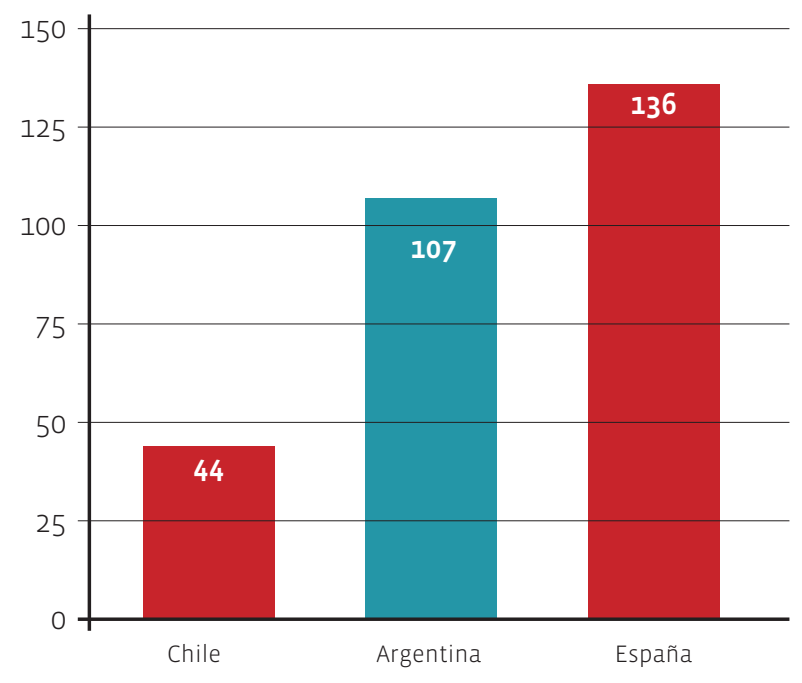

\section{GRÁFICO 5}

Agencias de traducción internacionales por país

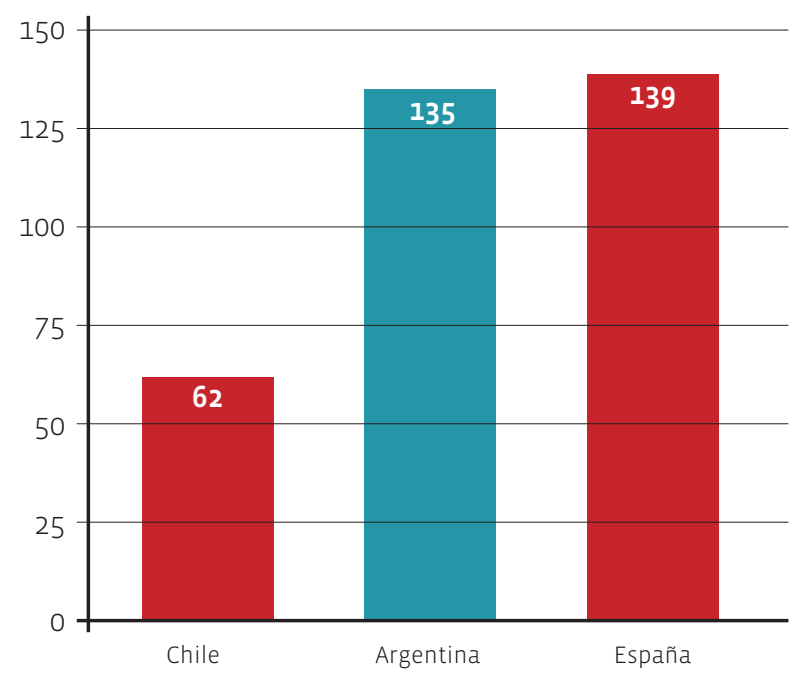

\subsection{Modalidades de traducción}

Los datos permiten confirmar que la mayoría de los encuestados practica la traducción escrita (732). La segunda modalidad de trabajo más mencionada es la interpretación (171) y, muy cerca de ella, la localización de sitios web (134). La localización de software (95) y la subtitulación (85) se ubican en un lugar intermedio. Llama la atención la poca frecuencia de la modalidad de doblaje (18) en los resultados. De los 36 traductores que marcaron la alternativa "otras modalidades", se destacan trabajos como revisor, subtitulado para hipoacúsicos y grabación de voz, entre otras.

\section{GRÁFICO 6}

Modalidades de traducción

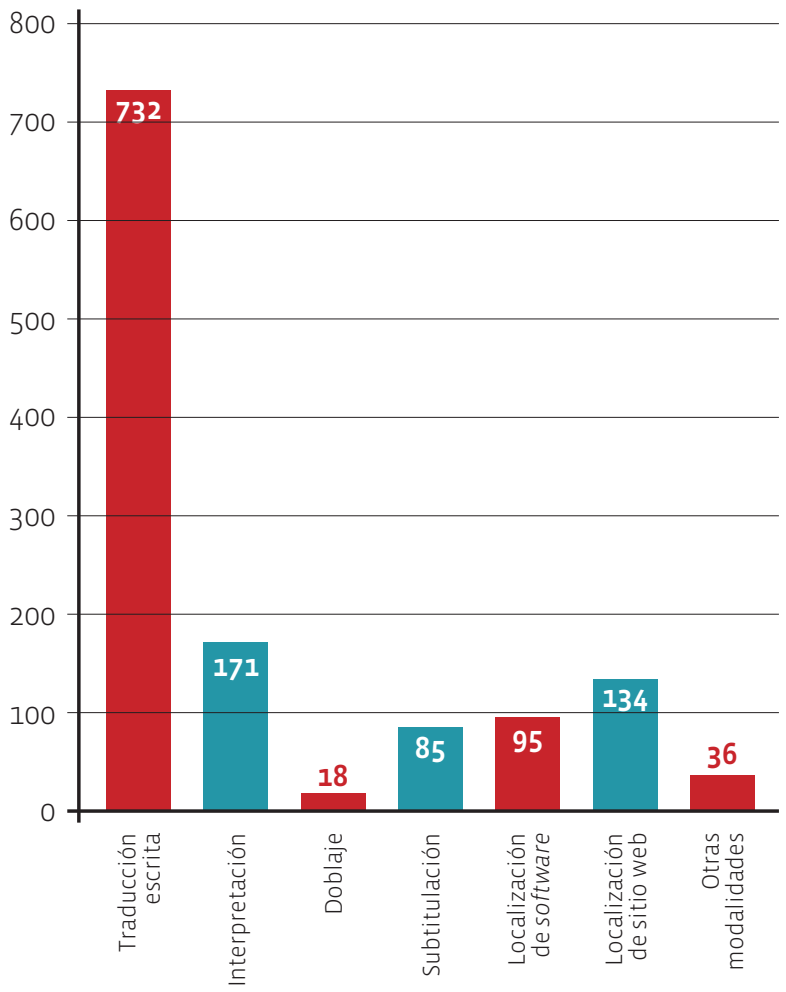

Al revisar los resultados por país se puede apreciar que en cuanto a las dos primeras modalidades, "traducción escrita" (Argentina 279, Chile 202 y España 251) e "interpretación" (Argentina 51, Chile 55 y España 65), las cifras se distribuyen de manera relativamente similar en 
los tres países. En lo que se refiere a localización de software (Argentina 41, Chile 18 y España 36) y localización de sitios web, (Argentina 51, Chile 36 y España 47), Chile presenta cifras comparativamente menores que Argentina y España (cf. gráficos 7 y 8). De los traductores que señalaron trabajar en doblaje y subtitulación, se observa que España concentra su trabajo en doblaje, con la mitad de las respuestas (Argentina 4, Chile 5 y España 9), y Argentina concentra gran parte de las respuestas en subtitulación (Argentina 40, Chile 20 y España 25).

\section{GRÁFICO 7}

Modalidad localización de software

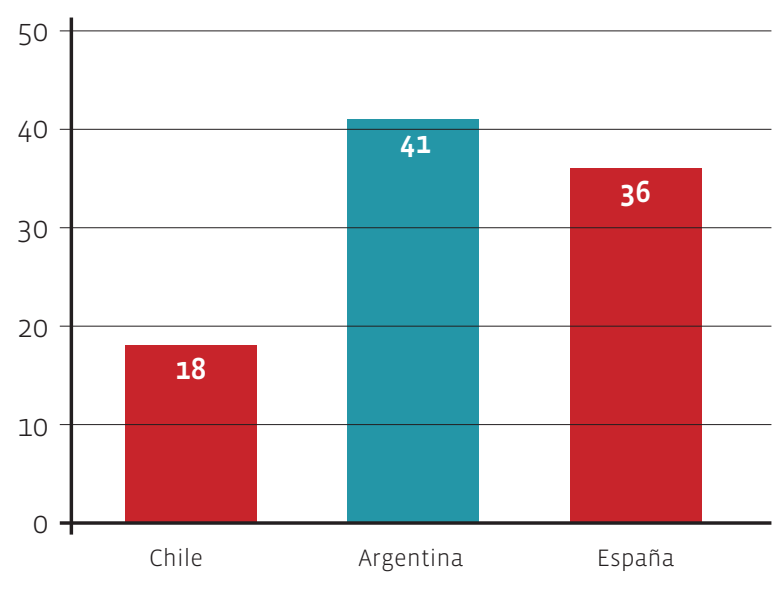

\section{GRÁFICO 8}

Modalidad localización de sitios web

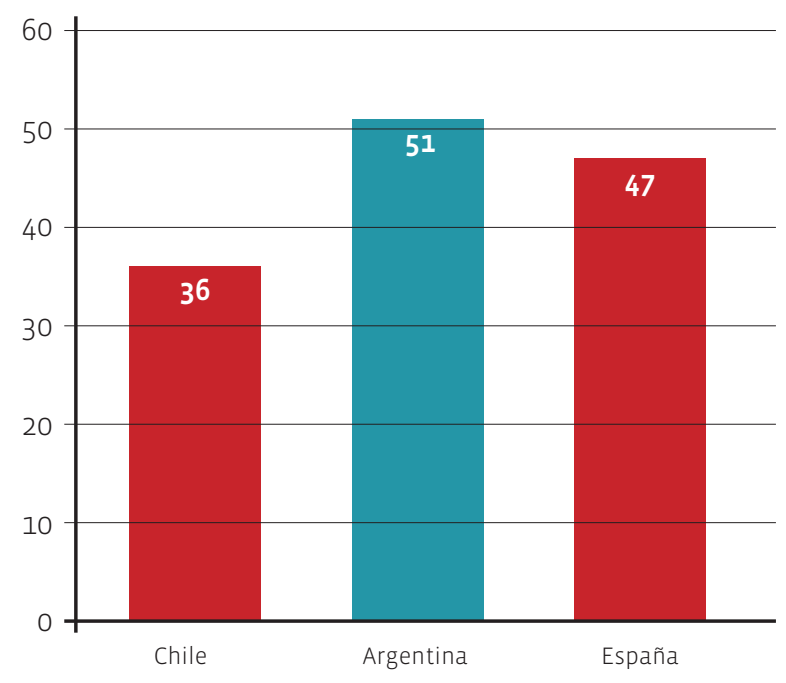

\subsection{Formato de documentos de trabajo}

Al observar los resultados por país, podemos comprobar que los traductores residentes de Argentina y Chile señalan con mayor frecuencia que "a veces" reciben trabajos en papel (115 y 91, respectivamente), seguido en nivel de frecuencia por "nunca" (Argentina 101 y Chile 53). En el caso de España, el mayor número de traductores señala no recibir "nunca" (111) trabajos en papel, seguido por la opción “a veces” (86).

\section{GRÁFICO 9}

Formato en papel

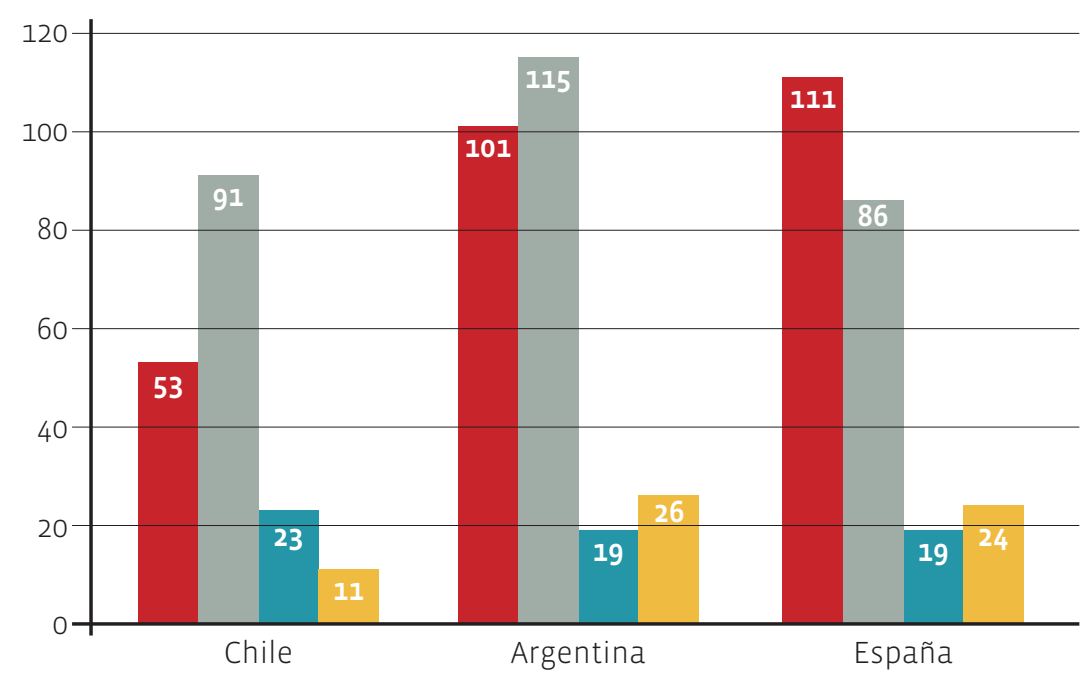

En papel (fotocopias, fax, textos originales impresos)

- Nunca

A veces

- Con frecuencia

- Con mucha frecuencia 
En cuanto a los archivos de texto (.doc), los tres países presentan cifras similares. Los traductores encuestados señalaron recibir este tipo de formato "con mucha frecuencia" (Argentina 192, Chile 146 y España 186), seguido de la opción "con frecuencia” (Argentina 60, Chile 40 y España 44). En el caso de los documentos de PowerPoint, la mayoría de los traductores de los tres países señalan que reciben "a veces" documentos en este formato, seguido de la opción "con frecuencia" (Argentina 84/67, Chile 66/49 y España 104/50).

En el caso de los documentos en formato .rtf, las cifras son dispares entre los países. En el caso de Chile, la mayoría de los traductores señalan que "nunca" (59) reciben documentos en este tipo de formato, seguido por "a veces" (41). Los residentes en Argentina, por el contrario, señaIan que "con mucha frecuencia" (60) reciben documentos en este tipo de formato, seguido de "a veces” (59). Por último, en el caso de España, las cifras se asemejan más a los resultados de Chile, ya que la mayoría de los traductores señalan que "a veces" (65) reciben este tipo de formato, seguido de la opción "nunca” (53).

En cuanto a los documentos en formato .pdf, Argentina y España presentan cifras simila- res, pues la mayoría de los traductores de ambos países señalan que "con frecuencia" (Argentina 93 y España 83) reciben documentos en este tipo de formato, seguido muy de cerca por la opción "con mucha frecuencia" (Argentina 91 y España 79). En el caso de Chile, la mayor parte de los traductores respondió que recibe documentos en este tipo de formato "con mucha frecuencia" (76), seguido de la opción "con frecuencia” (64).

Los traductores de los tres países señalan mayoritariamente que "a veces" reciben documentos en formato xls (Argentina 95, Chile 71 y España 87). En el caso de España y Argentina, la segunda opción es "con frecuencia" (62 y 51, respectivamente); sin embargo, en el caso de Chile, la segunda opción es "nunca" (45). Nuevamente, en cuanto a formatos .html y .xml, España y Argentina presentan tendencias similares. La mayoría de los traductores residentes en dichos países (88 y 76, respectivamente) señalan que "a veces" reciben documentos en dichos formatos, seguido de la opción "nunca". En el caso de Chile, la mayor parte de los traductores señala que "nunca" (64) recibe documentos en este tipo de formato, seguido de la opción "a veces" (cf. gráfico 10).

\section{GRÁFICO 10}

Formato .html y .xml (páginas web)

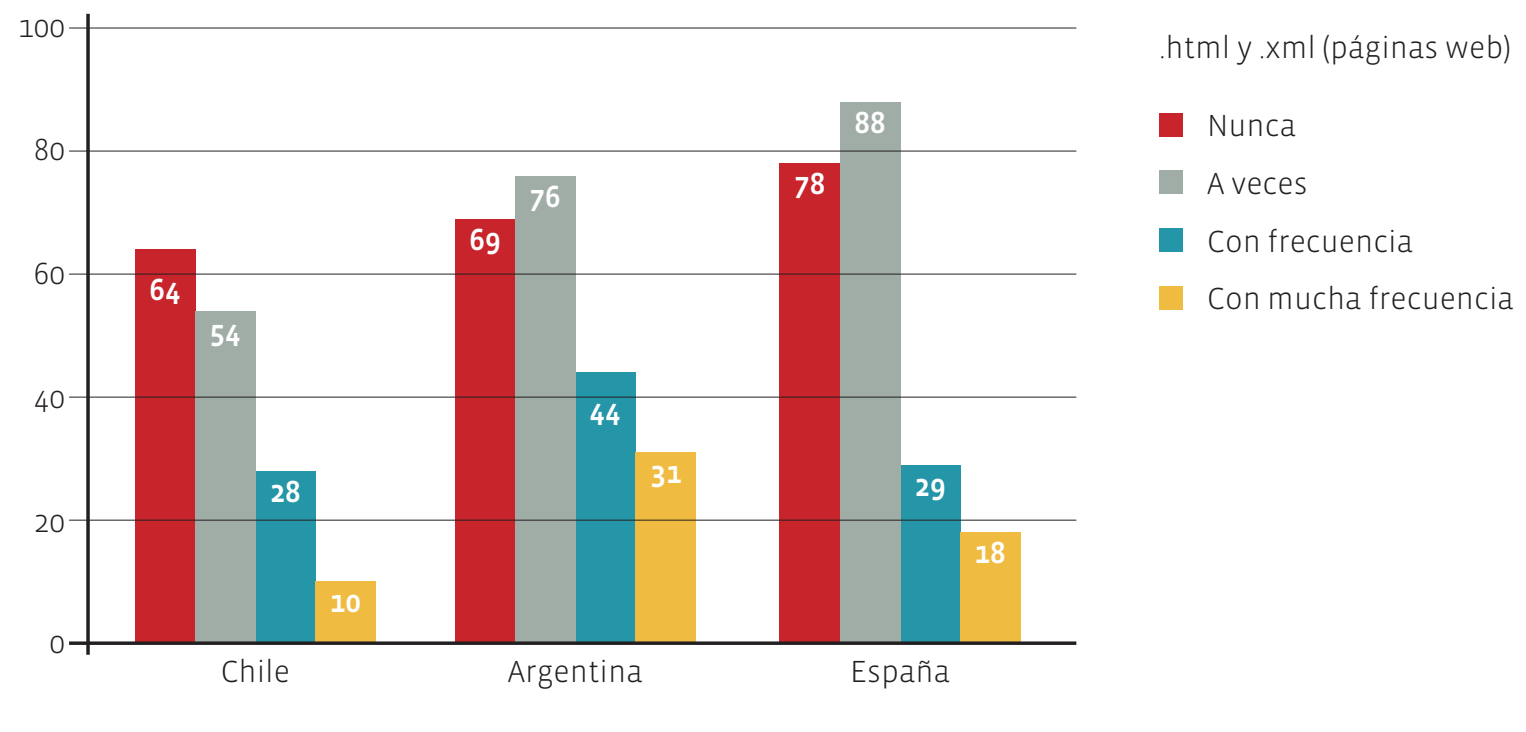


En cuanto a los documentos en formato CAT (traducción asistida por computador), la mayoría de los traductores de los tres países coinciden en indicar que "nunca" (Argentina 91, Chile 108 y España 101) reciben documentos en este tipo de formato. En todo caso, un número mayor de traductores de Argentina (64) y España (49), a diferencia de Chile (19), indican como segunda opción "con mucha frecuencia".

En el caso de videos y(o) películas, se presentan cifras coincidentes en los tres países dado que la mayor parte de los traductores señala que "nunca" recibe este tipo de documentos, seguido de la opción "a veces" (Argentina 126/55, Chile 94/41 y España 133/37). Cabe destacar por último que 33 traductores especificaron que trabajaban con otros tipos de formatos, como, por ejemplo, mp3, cintas de audio y Autocad.

\subsection{Uso y nivel de dominio de recursos informáticos}

Iniciaremos el análisis de esta sección describiendo aquellos recursos informáticos que no son usados frecuentemente por los traductores profesionales, aquellos en que no existe coincidencia en su uso en los diferentes países, para luego abocarnos a la descripción de aquellas herramientas que usan con mayor frecuencia los traductores encuestados.

En cuanto al uso del sistema operativo Linux, una cantidad mayor de traductores señala no utilizar esta herramienta informática, comparado con quienes la utilizan (Argentina 135/7, Chile 98/7 y España 137/21). Cabe destacar que este sistema operativo es mucho más utilizado por traductores que residen en España (21) en comparación con los dos países latinoamericanos (7), un tercio de la cifra que exhibe España. Algo similar ocurre en el caso de Mac OS, ya que la mayor parte de los traductores de los tres países no lo utiliza (Argentina 133, Chile 96 y España 131), si bien nuevamente se observa que un porcentaje mayor de traductores residentes en
España (37) lo utiliza, en comparación con Chile (12) y Argentina (8).

En lo que respecta al uso del programa Practicount, se observa una marcada tendencia a prescindir de esta herramienta entre los traductores de los tres países (Argentina 121, Chile 93 y España 144), si bien cabe destacar que un número mayor de traductores residentes en Argentina (32) utilizan este programa, si comparamos las cifras con las de Chile (15) y España (15). Al ver lo que ocurre con el uso de Dropbox, se observa una tendencia relativamente similar en los tres países, ya que la mayoría señala no utilizar dicha herramienta, en comparación con quienes la utilizan (Argentina 113/45, Chile 79/42 y España 94/81), si bien en el caso del país europeo la distribución entre quienes no la usan (94) y quienes la usan (81) es más estrecha que en el caso de Chile y Argentina.

En el caso del sistema operativo Windows Vista, en los tres países es mayor el número de traductores que no lo utiliza que quienes lo emplean en su trabajo (Argentina 106/67, Chile 73/46 y España 107/74). Similar situación ocurre con los programas de telefonía IP, dado que la mayoría de los traductores de los tres países afirman que no utilizan esta herramienta de comunicación gratuita, si bien el número de traductores que la utiliza es relativamente cercano a la cifra anterior (Argentina 95/64, Chile 73/45 y España 105/71).

El uso de Abbyy FineReader se distribuye de manera similar en los traductores residentes en Chile y Argentina y las cifras de quienes no lo utilizan y quienes lo emplean son más cercanas que en el caso de Linux y Practicount (Argentina 89/84, Chile 72/59 y España 123/46). En el caso de los traductores residentes en España, la distancia entre los que no utilizan el programa (123) y quienes lo utilizan (46) es bastante más marcada.

En cuanto al uso de los Exploradores de FTP, observamos que en el caso de los residentes de Argentina y España una mayor cantidad de tra- 
ductores utiliza esta herramienta (Argentina 118 y España 104), en comparación con quienes no la utilizan (Argentina 63 y España 79). La mayoría de los traductores residentes en Chile, por su parte, afirman no utilizar dichos programas (67), si bien un número relativamente similar (51), pero menor, reconoce que utiliza dicha herramienta.

Las cifras que se observan sobre el uso de software de OCR nos muestran una similitud en el caso de los traductores residentes en Chile y España; en efecto, los traductores de ambos países señalan mayoritariamente que no utilizan estas herramientas (Chile 69 y España 95), si bien un número relativamente menor señala que usa este tipo de software en su trabajo (Chile 58 y España 86). En el caso de los traductores residentes en Argentina, la tendencia es opuesta, dado que un número mayor de profesionales (90) afirma utilizar algún programa de OCR, seguido de una cifra relativamente menor de traductores (80) que no utiliza ninguno.

La mayoría de los traductores residentes en los tres países señalan que utilizan Windows XP en su trabajo profesional como traductor, comparado con quienes señalan no utilizarlo (Argen- tina 199/38, Chile 133/36 y España 165/51). A su vez, los traductores residentes en los tres países consideran que su nivel es de usuario avanzado (Argentina 132, Chile 73 y España 116), si bien en el caso de los profesionales residentes en Chile, la cifra es comparativamente menor que en los otros dos países.

Podemos afirmar que existe una tendencia similar en el caso del uso de Windows 7 en los tres países, si bien en este caso es más estrecha la relación entre quienes lo utilizan y quienes no lo utilizan en su trabajo (Argentina 142/70, Chile 110/44 y España 112/74), en comparación con el uso de Windows XP. Las cifras relativas al nivel de competencia en el uso de este sistema operativo son bastante similares en el caso de Argentina y España, dado que la mayoría de los traductores residentes en dichos países señalan ser usuarios avanzados (Argentina 83 y España 78), seguidos relativamente de cerca por aquellos que se consideran usuarios intermedios (53 en ambos países). En el caso de los traductores residentes en Chile, la tendencia es opuesta ya que la mayoría señala ser usuario intermedio (56), seguido de cerca por aquellos que se consideran usuarios avanzados (49).

\section{GRÁFICO 11}

Nivel de Windows 7

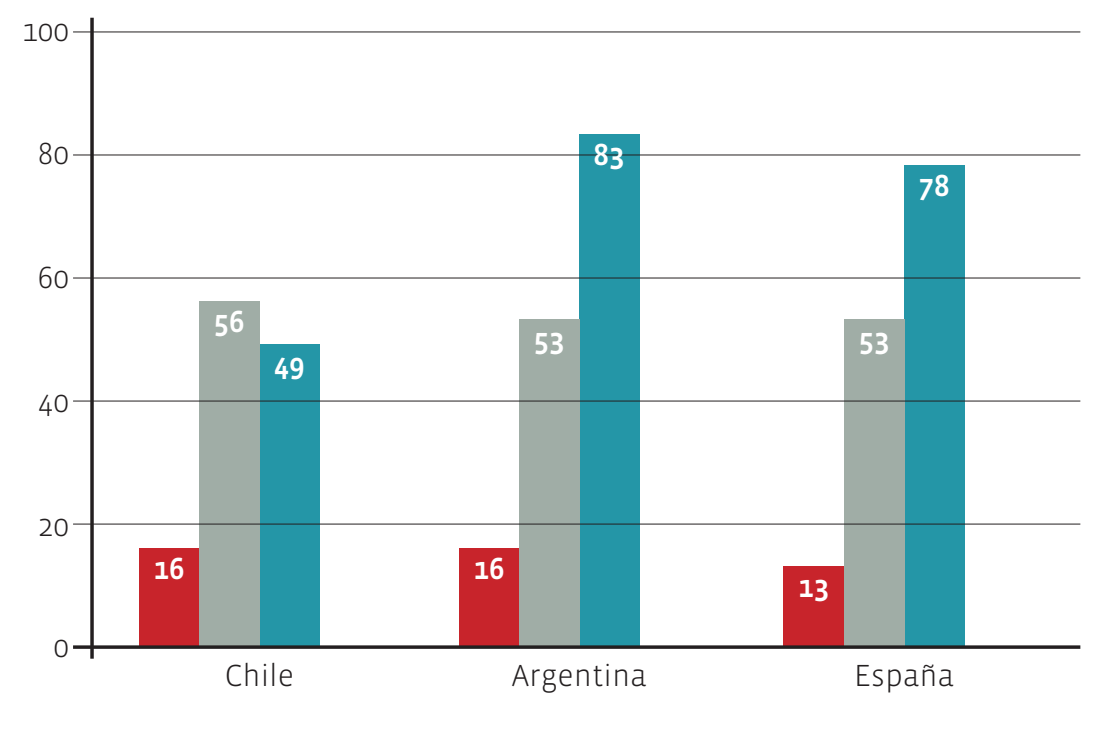

Windows 7

- Nivel de usuario básico

- Nivel de usuario intermedio

- Nivel de usuario avanzado 
En cuanto al uso del procesador de textos Word, las cifras de los tres países muestran un empleo muy elevado por parte de los traductores encuestados, en comparación con quienes declaran no utilizarlo (Argentina 267/3, Chile 195/3 y España 247/3). A su vez, las cifras son bastante similares en los tres países en cuanto al nivel de usuario de este procesador de textos; en efecto, la gran mayoría de los traductores señala poseer un nivel avanzado de manejo de Word y una cifra muy reducida se reconoce como usuario básico de dicha herramienta (Argentina 205/6, Chile 123/7 y España 189/7).

Algo similar ocurre con el uso de la planilla de cálculo Excel, dado que la mayor parte de los traductores de los tres países reconoce que utiliza esta herramienta de Office, aunque el porcentaje de traductores que no utiliza el programa es relativamente mayor en comparación con las cifras referidas al programa Word (Argentina 237/11, Chile 162/14 y España 222/18). Si bien la tendencia general en los tres países es bastante similar en cuanto al nivel de dominio de Excel, cabe destacar que las cifras son muy similares en el caso de Argentina y España. Los traductores residentes en dichos países se consideran usuarios intermedios de dicha herramienta (Argentina 106 y España 96), seguidos muy de cerca por los usuarios avanzados (Argentina 103 y España 93). En el caso de Chile, se aprecia una diferencia mayor entre quienes se consideran usuarios intermedios (88), que corresponde a una cifra casi el doble de los usuarios avanzados (45).

Una tendencia muy similar a la del programa Excel se observa en el caso del uso del programa PowerPoint, dado que la mayoría de los traductores residentes en los tres países señala utilizar dicho programa, en comparación con quienes señalan no utilizarlo (Argentina 219/20, Chile 157/14 y España 201/27). En lo que respecta al nivel de usuario de PowerPoint, se puede observar que las cifras son muy similares a las de Excel; en efecto, los traductores residentes en Argentina y España presentan datos muy simila- res. La mayoría se considera usuario intermedio de PowerPoint (Argentina 104 y España 94), seguido muy de cerca por aquellos usuarios avanzados del programa (Argentina 98 y España 85). En el caso de Chile la diferencia entre quienes se consideran usuarios intermedios y avanzados es más marcada, dado que los usuarios avanzados corresponden a aproximadamente la mitad (53) de los usuarios intermedios (95).

En lo que se refiere a buscadores en Internet, comprobamos que la amplia mayoría de los traductores residentes en los tres países los utiliza para realizar su trabajo profesional, comparado con quienes señalan no utilizarlos (Argentina 265/2, Chile 192/2 y España 242/1). En lo que respecta al nivel de usuario, se aprecia una tendencia similar al uso del procesador de textos Word, dado que una amplia mayoría de los traductores residentes en los tres países se considera usuario avanzado de este recurso en línea (Argentina 177, Chile 119 y España 182). En este caso, las cifras de usuarios intermedios y básicos son bastante reducidas.

Nuevamente se presentan cifras similares en cuanto al uso de portales para traductores, ya que la mayoría de los profesionales de los tres países señala usar este tipo de herramienta informática en su trabajo profesional, si lo comparamos con quienes declaran no utilizarlos (Argentina 247/8, Chile 171/10 y España 223/14). En cuanto al nivel de competencia en el uso de portales para traductores, llama la atención que las cifras de Argentina y España difieren de las que se observan en el caso de los traductores residentes en Chile. Los traductores residentes en Argentina y España se consideran mayoritariamente usuarios avanzados de dichos portales, 138 y 124, respectivamente. En el caso de Chile, en cambio, la mayoría se considera usuario intermedio (72) seguido muy de cerca por aquellos que se consideran usuarios avanzados (68).

El programa Winzip, que permite comprimir archivos, es ampliamente utilizado por los traductores residentes en los tres países, comparado 


\section{GRÁFICO 12}

Nivel de portales para traductores

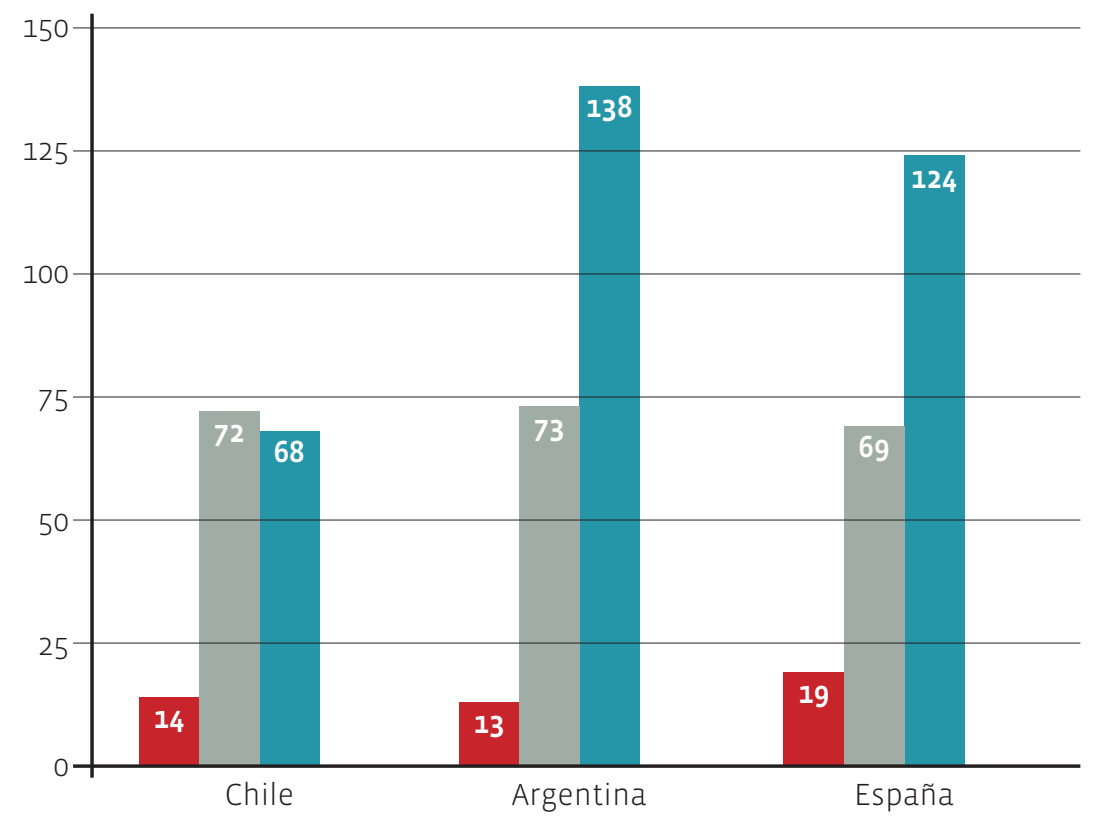

Portales para traductores (Proz, etc.)

- Nivel de usuario básico

- Nivel de usuario intermedio

nivel de usuario avanzado

con quienes no lo emplean (Argentina 223/13, Chile 148/14 y España 200/18). Respecto del nivel de manejo del programa, los traductores residentes en Argentina y España presentan cifras similares, dado que la mayoría de los traductores se considera usuario avanzado del programa (Argentina 95 y España 82), seguidos de cerca por aquellos usuarios de nivel intermedio (Argentina 79 y España 76). En el caso de los traductores residentes en Chile, la mayoría se considera usuario intermedio (62), seguido por los usuarios avanzados (48)

Por último, cabe acotar que un total de 80 traductores especificaron que utilizaban en su trabajo profesional otros recursos informáticos entre los que cabe destacar Babylon, Yousendit. com y Count Anything.

\subsection{Uso y nivel de dominio de memorias de traducción y programas relacionados}

Al igual que en la descripción de los recursos informáticos, comenzaremos por aquellos programas que mayoritariamente no utilizan los traductores para terminar con la descripción de los más utilizados y su nivel de dominio.
El programa Transsearch es el menos utilizado por los traductores de los tres países, ya que las cifras de quienes no lo utilizan y quienes lo emplean son bastante extremas (Argentina 165/1, Chile 130/o y España 160/2). En el caso de Chile, se observa que ningún traductor utiliza esta herramienta y en los casos de Argentina y España, las cifras son muy bajas. Los datos sobre el manejo de Plus Tools son similares a los de TransSearch dado que la mayoría de los traductores residentes en los tres países reconoce que no utiliza dicha herramienta y muy pocos reconocen utilizarla (Argentina 157/12, Chile 125/8 y España 157/11).

Asimismo, los datos demuestran que la memoria de traducción Déja Vu es muy poco utilizada por los traductores residentes en los tres países, comparado con quienes la emplean (Argentina 150/22, Chile 126/10 y España 149/28). Cabe destacar que la cifra de traductores de España que utilizan esta herramienta (28) es relativamente mayor que la de los traductores de Argentina (22) y casi el triple de los traductores residentes en Chile (10). Las cifras de uso del pro- 
grama OmegaT son muy similares a las que se presentan para la memoria de traducción Déja Vu. En efecto, la mayoría de los traductores de los tres países reconoce no utilizar esta herramienta y una cifra reducida declara emplearlo en su trabajo (Argentina 145/19, Chile 122/10 y España 143/25). En este caso, el número de traductores de España (25) que utiliza esta herramienta es más del doble de los traductores residentes en Chile (10).

En cuanto al uso del programa Passolo, podemos concluir que se trata de una herramienta muy poco utilizada por los traductores residentes en los tres países, dado que un número muy inferior reconoce emplearlo, comparado con quienes declaran utilizarlo en su trabajo (Argentina 149/23, Chile 121/15 y España 140/32). Cabe señalar que el doble de los traductores residentes en España señala que lo utiliza (32) frente a la cifra que se exhibe en el caso de Chile (15). A la luz de los resultados sobre el uso del programa Catalyst, podemos señalar que la tendencia es muy similar a la del programa Passolo, puesto que muy pocos traductores en los tres países señalan utilizar la herramienta, frente a quienes reconocen no utilizarla (Argentina 151/7, Chile 127/17 y España 152/16).

Las cifras que se presentan sobre el uso del programa de reconocimiento de voz, Dragon Naturally Speaking, son muy similares a las de los dos programas anteriores, puesto que en los tres países se observa un porcentaje muy elevado de traductores que no utilizan la herramienta frente a quienes la utilizan (Argentina 148/20, Chile 113/16 y España 148/32). Cabe destacar que los traductores residentes en España que utilizan el programa (32) corresponden al doble de los traductores residentes en Chile que afirman utilizar la herramienta (16). Por último, llama la atención que de los tres programas de la suite SDL Trados, la mayoría de los traductores de los tres países reconoce que no utiliza el programa de alineamiento de textos Winalign, comparado con quienes señalan utilizarlo (Argentina 112/93, Chile
107/36 y España 110/75). Se observa que la diferencia entre los residentes en Argentina y España es menos marcada entre quienes no utilizan la herramienta y quienes la utilizan, frente a las cifras que presentan los traductores residentes en Chile.

A continuación presentamos la descripción de las memorias de traducción y programas relacionados que utilizan con mayor frecuencia los traductores encuestados y el grado de dominio que tienen de dichos programas.

Al comparar los datos por país referidos a la memoria de traducción Wordfast, observamos que estos no se distribuyen en forma equilibrada entre quienes la utilizan y quienes no la utilizan en su trabajo (Argentina 118/95, Chile 54/106 y España 76/123). En efecto, Ios traductores residentes en Chile y España presentan cifras relativamente similares dado que quienes no la utilizan (Chile 106 y España 123) corresponden a aproximadamente el doble de quienes la utilizan (Chile 54 y España 76). En el caso de Argentina, podemos observar que un número mayor de traductores (118) señala utilizar la herramienta, frente a quienes no la utilizan (95) en su trabajo. La mayoría de los traductores residentes en los tres países se consideran usuarios básicos de Wordfast (Argentina 57 Chile 60 y España 63), si bien en el caso de Argentina las cifras son bastante similares entre quienes se consideran usuarios básicos (57), intermedios (54) y avanzados (41). En los casos de Chile y España las cifras presentan mayores diferencias, como se observa en el gráfico 13.

En cuanto al uso del programa Tag Editor, las cifras de Chile son diferentes a las que presentan Argentina y España. En efecto, los traductores residentes en estos últimos dos países señalan en su mayoría que utilizan la herramienta, comparado con quienes no lo utilizan (Argentina 142/82 y España 124/81), en cambio la mayor parte los traductores residentes en Chile reconoce no utilizar dicho programa (98) y aproximadamente la mitad de ellos afirma que la utiliza (55). 


\section{GRÁFICO 13}

Nivel de dominio de Wordfast

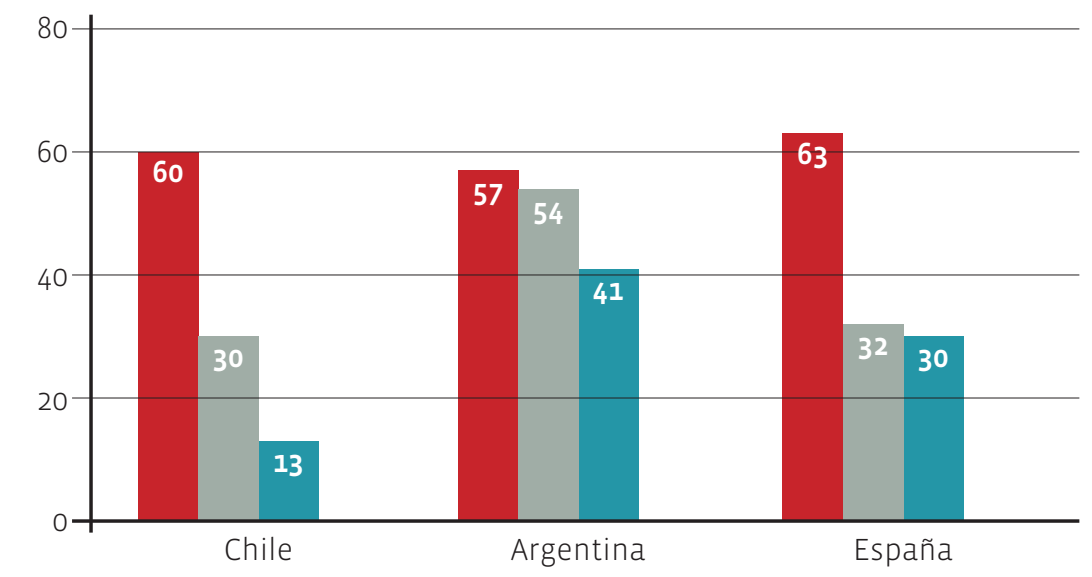

Wordfast

- Nivel de usuario básico

- Nivel de usuario intermedio

nivel de usuario avanzado

En lo que respecta al nivel de usuario reportado para Tag Editor, nuevamente las cifras de Argentina y España son relativamente similares y difieren con las de Chile. En los primeros dos países, la mayoría de los traductores se consideran usuarios avanzados del programa (Argentina 77 y España 61), en cambio los usuarios avanzados de Chile son solo 18 traductores. En este último país la mayoría se declara usuario básico (55), seguido de los usuarios intermedios (28) (cf. gráfico 14).

En cuanto al uso del programa Multiterm, las cifras presentan una tendencia similar a la del programa Tag Editor. Los traductores residentes en Argentina y España señalan en su mayoría que utilizan este programa de gestión terminológica (Argentina 113 y España 96, respectivamente), si bien se observa que un número levemente inferior de traductores reconoce no utilizarlo (Argentina 100 y España 92). En el caso de Chile, en cambio, la mayoría de los traductores (101) declara no utilizar la herramienta y aproximadamente menos de la mitad (47) afirma que la utiliza.

Los datos sobre el nivel de usuario del programa de gestión terminológica Multiterm son relativamente similares en los tres países dado que la mayoría de los traductores se considera usuario básico del programa. En el caso de Argentina las cifras son iguales entre quienes se

\section{GRÁFICO 14}

Nivel de dominio de Tag Editor

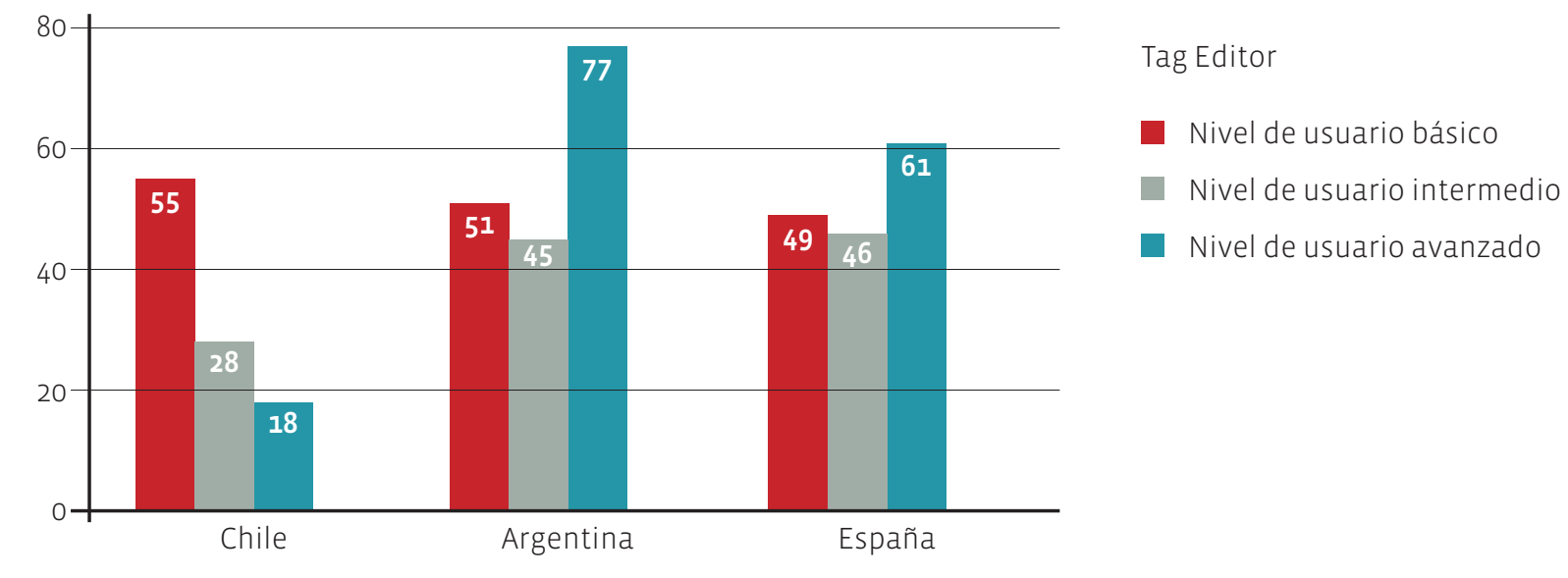




\section{GRÁFICO 15}

Nivel de dominio de Multiterm

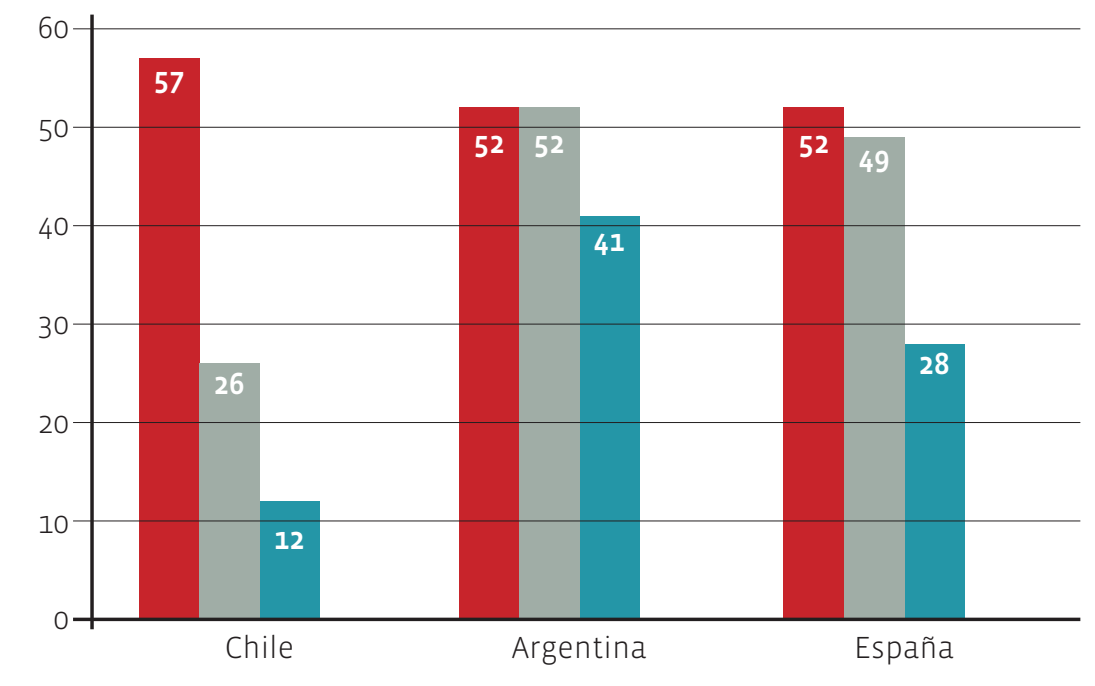

\section{Multiterm}

Nivel de usuario básico

- Nivel de usuario intermedio

Nivel de usuario avanzado consideran usuarios básicos e intermedios (52), tendencia bastante similar en España. En el caso de Chile, las diferencias son más marcadas en los tres niveles de usuarios, pues los usuarios avanzados representan la cifra menor (12), comparada con la cifra que presentan Argentina (41) y España (28) (cf. gráfico 15).

Finalmente, las cifras referidas al uso del Workbench de la suite SDL Trados demuestran que es el programa de la suite SDL Trados más utilizado por los traductores de los tres países, comparado con todos los programas consultados en la encuesta (Argentina 191/63, Chile 99/74 y España 149/71). En cuanto a los datos de Chile, se observa que la relación entre quienes utilizan Workbench (99) y quienes no lo utilizan (74) es menos marcada frente a lo que se observa en el caso de Argentina (191/63) y España 149/71). En

\section{GRÁFICO 16}

Nivel de dominio de SDL Trados (Workbench)

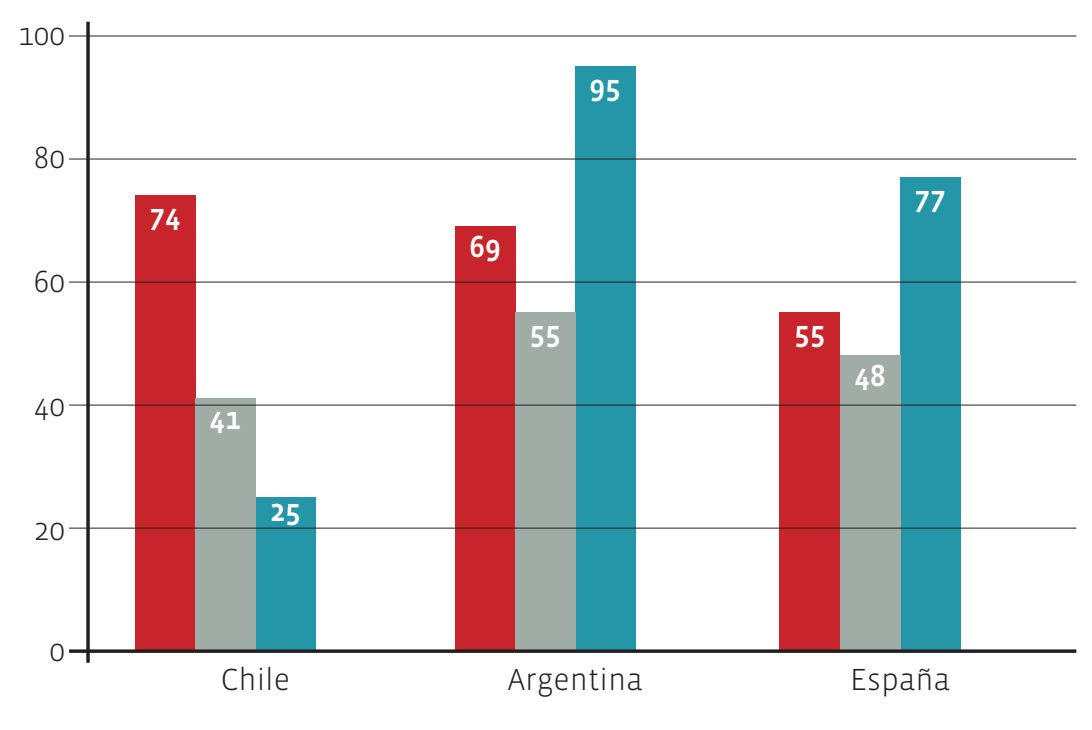

SDL Trados (Workbench)

- Nivel de usuario básico

- Nivel de usuario intermedio

Nivel de usuario avanzado 
cuanto al nivel de usuario de este programa, podemos observar que las cifras de Chile difieren de las de Argentina y España. Estos últimos países exhiben cifras similares dado que la mayoría de los traductores se consideran usuarios avanzados de la herramienta (Argentina 95 y España 77). En el caso de Chile, solo 25 traductores se reconocen como usuarios avanzados frente a 74 que se consideran usuarios básicos de la memoria de traducción (cf. gráfico 16).

Cabe destacar por último que 103 traductores especificaron el uso de otras memorias de traducción como, por ejemplo, Star Transit, Memo Q y Across.

\section{Conclusiones}

A continuación se presentan las conclusiones de los datos obtenidos en el estudio de mercado 2011 y, en el caso de algunos ítems referidos a los traductores residentes en Chile, se realiza una comparación con los datos recabados en las encuestas 2006 y 2008.

\subsection{Formas de trabajo}

Los datos generales obtenidos nos permiten concluir, en primer lugar, que la labor que realizan los traductores residentes en los tres países corresponde principalmente a un servicio externalizado. Más de la mitad de los encuestados señala que trabaja en forma independiente, ya sea de manera totalmente in dependiente o combinando esta modalidad con el trabajo en alguna organización. Las formas de trabajo que implican un contrato de planta exhiben cifras comparativamente bajas Los resultados por país presentan la misma tendencia que los resultados generales, dado que la alternativa "Trabajo jornada completa en forma independiente" es la más frecuente en los tres países, superando ampliamente a las demás formas de trabajo.
Ahora bien, si comparamos los resultados de las encuestas 2008 y $2011^{2}$ de los traductores residentes en Chile en lo que respecta a su forma de trabajo, podemos concluir que en general se mantiene la misma tendencia en ambas encuestas. En efecto, los porcentajes de respuestas más elevados en ambas encuestas corresponden a las alternativas "trabajo jornada completa independiente" (37,9\% en 2011 y $38,1 \%$ en 2008) y "trabajo en una empresa y además en forma independiente" (24,1\% en 2011 y $27,2 \%$ en 2008). En tercer lugar se presenta la alternativa "trabajo jornada completa contratado" con porcentajes bastante menores (7,9\% en 2011 y 9,9\% en 2008). Esto nos permite concluir que la mayoría de los traductores residentes en Chile trabaja en forma independiente, lo que corroboraría que la traducción en nuestro país es un servicio cada vez más externalizado.

\subsection{Tipos de clientes}

Por otra parte, los datos generales sobre los tipos de clientes reflejan un grado cada vez mayor de internacionalización del servicio de traducción, puesto que los tipos de clientes más frecuentes de los traductores independientes son, después de los "clientes directos nacionales", las "agencias de traducción internacionales", que superan a las "agencias de traducción nacionales". Llama la atención también que en cuarto lugar se presentan los "clientes directos internacionales". A este nivel de internacionalización han contribuido las TIC aplicadas a la traducción que han permitido a los profesionales una comunicación ubicua tanto con clientes como con colegas en todo el mundo. Cabe destacar que la internacionalización del servicio se evidencia menos en nuestro país si observamos las cifras sobre "Agencias de traducción internacionales" (Argentina 135, Chile 62 y España 139), donde Chile exhibe una cifra menor. Este tipo de clientes es el que generalmente publica trabajos 
en portales para traductores y el que mayormente promueve el trabajo en equipo para proyectos de traducción de gran envergadura que exigen del profesional un dominio avanzado de las TIC aplicadas a la traducción.

Si comparamos los resultados sobre tipos de clientes de los traductores residentes en Chile en las encuestas 2008 y $2011^{3}$, podemos afirmar, al igual que en el caso de las formas de trabajo, que las cifras son similares en las dos encuestas. En efecto, el tipo de cliente más frecuente en ambas encuestas corresponde a "clientes directos nacionales" (43,5\% en 2011 y 39,4\% en 2008); en segundo lugar se ubican los "clientes directos internacionales" (22,4\% en 2011 y $20,1 \%$ en 2008 ) seguidos de las "agencias de traducción internacionales" (16,8\% en 2011 y 13,2\% en 2008) y luego las "agencias de traducción nacionales" (11,9\% en 2011 y 13,2\% en 2008). En el caso de la encuesta 2011, las agencias nacionales ocupan el cuarto lugar con el menor número de respuestas; en la encuesta 2008, ambos tipos de agencias exhibían el mismo porcentaje. Estos datos reflejan una leve tendencia a una mayor internacionalización del servicio de traducción en nuestro país.

\subsection{Modalidades de traducción}

En cuanto a las modalidades de traducción de mayor demanda entre los encuestados, ítem que no se incluyó en las encuestas 2006 y 2008, confirmamos que la traducción escrita es la modalidad más frecuente (732), seguida de la interpretación con un margen de diferencia considerable (171). En tercer y cuarto lugar se ubican dos submodalidades de la localización, siendo la localización de sitios web más frecuente que la localización de software. Por último, el doblaje presenta una frecuencia muy baja y se concentra principalmente en los traductores residentes en España, mientras que los traductores residentes en Argentina realizan más trabajos de subtitulación que los residentes de Chile y España. En futuros estudios de mercado se podrá comparar la evolución de las modalidades de traducción en el trabajo de traductores profesionales.

\subsection{Tipos de formatos}

En lo que se refiere a los tipos de formatos de los documentos que los traductores reciben para traducir, se destaca el poco uso de material impreso en los tres países, en especial entre los residentes en España. Por el contrario, los documentos en formato electrónico .doc y .pdf son los más frecuentes en los tres países. Cabe destacar que los traductores residentes en Chile reciben menos encargos de traducción en formatos .xsl, .html y .xml que sus colegas de Argentina y España. Este hecho demuestra el menor dominio de las TIC aplicadas a la traducción por parte de los profesionales residentes en Chile.

Al comparar las respuestas de los traductores residentes en Chile en las encuestas 2011 y $2008^{4}$ en cuanto a tipos de formatos de los documentos a traducir, no se observan mayores diferencias. En efecto, al igual que en los resultados de la encuesta 2011, el formato impreso no era muy utilizado el año 2008 en nuestro país y, por el contrario, los formatos electrónicos .doc y .pdf eran muy frecuentes en los encargos de traducción. De igual forma, en 2008 los traductores en Chile no recibían con frecuencia documentos en formatos electrónicos .xls y .html.

\subsection{Recursos informáticos}

En cuanto al uso de recursos informáticos de apoyo a la labor del traductor, los menos utilizados por los traductores residentes en los tres países son Linux, Mac OS, Practicount, Dropbox, Windows Vista, telefonía IP y Abbyy FineReader. En el caso de los exploradores FTP y el software OCR, no existe coincidencia en cuanto al uso en los tres países; en efecto, el número de traductores residentes en Argentina y España que utili- 
zan los exploradores FTP es mayor que el de los profesionales residentes en Chile y el software OCR es utilizado por un mayor número de traductores residentes en Argentina, comparado con los profesionales de Chile y España.

Los sistemas operativos y programas más utilizados por los traductores residentes en los tres países son Windows XP, Windows 7, la suite Office (Word, Excel, PowerPoint), buscadores en Internet, portales para traductores y WinZip. Si bien en cuanto al uso de estos recursos informáticos no existen mayores diferencias entre los encuestados de los tres países, se observan diferencias en lo que respecta a su nivel de dominio. Vemos en los resultados que en casi todos los casos, los traductores residentes en Chile no reconocen un nivel avanzado de dominio de estos programas y sistemas operativos, a diferencia de los residentes de Argentina y España. Esta diferencia se manifiesta en Windows 7, Excel, PowerPoint, portales para traductores y demuestra que los profesionales residentes en nuestro país, como ya señalamos, exhiben un nivel menor de dominio de las TIC aplicadas a la traducción que sus pares de Argentina y España.

Al comparar los resultados sobre uso de recursos informáticos obtenidos por los traductores residentes en Chile en este estudio y los datos obtenidos en las encuestas 2006 y 2008, no se observan mayores diferencias. Los sistemas operativos que según el estudio 2011 son poco utilizados, como por ejemplo Linux y Mac OS, tampoco eran empleados con frecuencia por los traductores, según las dos encuestas anteriores. Solo Windows Vista presentaba en el año 2008 un uso mayor respecto de los resultados de la encuesta 2011, probablemente debido a la aparición el año 2009 de la versión Windows $7^{5}$. De igual forma, los recursos informáticos que según la encuesta 2011 usan con frecuencia los traductores residentes en Chile, como por ejemplo Word, Excel, PowerPoint, buscadores de Internet, portales para traductores y Winzip, también exhibían cifras elevadas de uso en los estudios 2006 y 2008. En lo que respecta al nivel de dominio de dichos recursos, se observan resultados similares en las tres encuestas con leves variaciones. En los programas Word, Excel y buscadores de Internet se presentan niveles de dominio similares a los resultados de la encuesta 2011. En cuanto a los programas PowerPoint y Winzip, se observa un nivel de dominio menor en las encuestas 2006 y 2008 a lo indicado en el estudio 2011.

\subsection{Memorias de traducción y progra- mas relacionados}

Finalmente, en cuanto al uso de memorias de traducción y programas relacionados, los menos utilizados corresponden a TransSearch, Plus Tools, Déja Vu, Omega T, Passolo, Catalyst, Dragon Naturally Speaking y Winalign de la suite SDL Trados. Por otra parte, las memorias de traducción y programas relacionados que más utilizan los traductores residentes en los tres países corresponden a Wordfast, Tag Editor, Multiterm y Workbench, estos tres últimos de la suite SDL Trados. En cuanto al nivel de dominio de estos programas, las cifras presentan resultados similares al de los recursos informáticos, puesto que los traductores residentes en Chile manifiestan un menor dominio de memorias de traducción como Tag Editor, Multiterm y Workbench que sus colegas residentes en Argentina y España, lo cual ratifica nuevamente un menor grado de dominio de las TIC aplicadas a la traducción.

Si contrastamos los resultados obtenidos de los traductores residentes en Chile en este estudio con los datos sobre uso de memorias de traducción y programas relacionados en las encuestas 2006 y 2008, al igual que en el caso del uso de recursos informáticos, no se observan mayores diferencias. En general los programas que según el estudio 2011 son poco utilizados, como

5 Estos datos no consideran el sistema operativo Windows 8, que comenzó a comercializarse en octubre de 2013. 
por ejemplo TransSearch y Déja Vu, tampoco lo son de acuerdo con las dos encuestas anteriores. De igual forma, las memorias de traducción que en la encuesta 2011 usan con frecuencia los traductores residentes en Chile, como por ejemplo el programa Workbench de la suite SDL Trados, también exhibían cifras elevadas de uso en los estudios 2006 y 2008. En lo que se refiere al grado de dominio de las memorias de traducción y programas relacionados, también observamos que no existen diferencias en las encuestas 2006 y 2008 respecto de los resultados del estudio 2011. Los programas Wordfast, Tag Editor y MultiTerm exhiben un bajo nivel de dominio de los traductores residentes en Chile, dado que en las tres encuestas la mayoría se declara usuario básico de dichas herramientas informáticas.

En síntesis, los datos recabados en los tres estudios de mercado realizados en los últimos ocho años nos han permitido corroborar, en lo que respecta a las TIC aplicadas a la traducción, la necesidad de desarrollar en el estudiante competencias para un trabajo profesional cada vez más externalizado e internacionalizado en el cual las TIC generales y específicas de apoyo a la labor del traductor profesional cobran especial relevancia. La inclusión de contenidos de la línea disciplinaria de teletraducción en el plan de estudios del Magíster y del Diploma que ofrece nuestra Universidad ha permitido formar y perfeccionar a profesionales preparados para enfrentar los desafíos que presenta actualmente la traducción a nivel nacional e internacional. El desafío es aún mayor al confirmar en el último estudio de 2011 el nivel comparativamente menor de dominio de las TIC generales y específicas por parte de los traductores residentes en nuestro país frente a sus pares de Argentina y España, lo cual ratifica la necesidad de ofrecer en Chile especialización en el ámbito de la teletraducción.

\section{Bibliografía citada}

Diéguez, María Isabel, Rosa María Lazo y Camilo QuezadA, 2012: Estudio de mercado de la traduc- ción en Argentina, Chile y España, documento interno, Santiago: Programa de Traducción, Facultad de Letras, Pontificia Universidad Católica de Chile.

Diéguez, María Isabel, Rosa María Lazo y Camilo QuezAdA, 2014: "Estudio de mercado de la traducción en Argentina, Chile y España: perfil académico y profesional de los traductores", Onomázein 30, 70-89.

Quezada, Camilo, 2006: Estudio de mercado de la traducción en Chile, documento interno, Santiago: Programa de Traducción, Facultad de Letras, Pontificia Universidad Católica de Chile.

Quezada, Camilo, 2008: Estudio de mercado de la traducción en Chile, documento interno, Santiago: Programa de Traducción, Facultad de Letras, Pontificia Universidad Católica de Chile. 